\title{
Differences between the evaluation of thermal environment in shaded and sunny position
}

\author{
NoÉMI KÁNTOR ${ }^{1}$
}

\begin{abstract}
Great attention has been paid in the last one and a half decade to the subjective evaluation of atmospheric conditions in different outdoor and semi-outdoor urban environments. Several field surveys were conducted all around the world in order to specify those physical and personal factors that influence the perception of thermal environment. Many studies reported about seasonal differences in the subjective assessment concerning thermal sensitivity as well as the so-called neutral temperature. The present investigation aims to reveal these seasonal differences in Hungary and to scrutinise the effect of solar exposure (staying in shaded position or in the sun) on these patterns. The analyses are based on a long-term outdoor thermal comfort project with 78 measurements days conducted on six recreational places in Szeged, Hungary. In the frame of the project thousands of people were asked about their actual thermal sensation and about their preference for any change regarding the thermal environment. Parallel to the questionnaire survey, detailed human bio-meteorological measurements were carried out in the vicinity of the questioned individuals. A well-established human bio-meteorological index was calculated from the measured atmospheric parameters: the Physiologically Equivalent Temperature (PET). Regression analysis was performed between the subjective and objective measures in order to specify neutral and preferred temperatures (nPET, $p P E T)$. Furthermore, in the case $p P E T$ values a new assignment procedure was also implemented building on probit model technique. The two analytical approaches resulted in very similar $p P E T$ values in every case when the sample size was sufficiently large. The study revealed much higher $p P E T$ than $n P E T$ values in every season; moreover, significant differences depending on the sun exposure of the subjects.
\end{abstract}

Keywords: subjective assessment, Physiologically Equivalent Temperature, neutral and preferred temperature, solar exposure

\section{Introduction}

The excessive level of urbanization (UNFPA 2011) and the projected challenges due to climate change (IPCC 2014) necessitate dealing with urban climate issues all around the world. Correspondingly, the number of studies with focus on the thermal conditions within cities is rapidly growing (CHEN, L. and NG, L. 2012; Rupp, R.F. et al. 2015). Several from the earlier investigations applied well-established human bio-meteorological indices, for example the Physiologically Equivalent Temperature - PET (HöpPE, P. 1999), in order to express the physiological and comfort aspects of small-scale meteorological conditions in outdoor urban spaces. A great portion of these examinations was built on micrometeorological measurements (e.g. MAYER, H. et al. 2008; Lin, T.-P. et al. 2010; HwANG, R.-L. et al. 2011; Gómez, F. et al. 2013), while others applied numerical models in order to simulate the consequences of different landscape design strategies on thermal comfort and human health (e.g. Fröhlich, D. and Matzarakis, A. 2013; Müller, N. et al. 2014). Most of the existing analyzes were based on the original threshold values of the applied index. In the case of the aforementioned PET index the category benchmarks (Figure 1) are based on the physiological reactions of a 'typical' Central European man (MatzaraKis, A. and Mayer,

\footnotetext{
${ }^{1}$ Department of Climatology and Landscape Ecology, University of Szeged. H-6722 Szeged, Egyetem u. 2. E-mail: sztyepp@gmail.com
} 


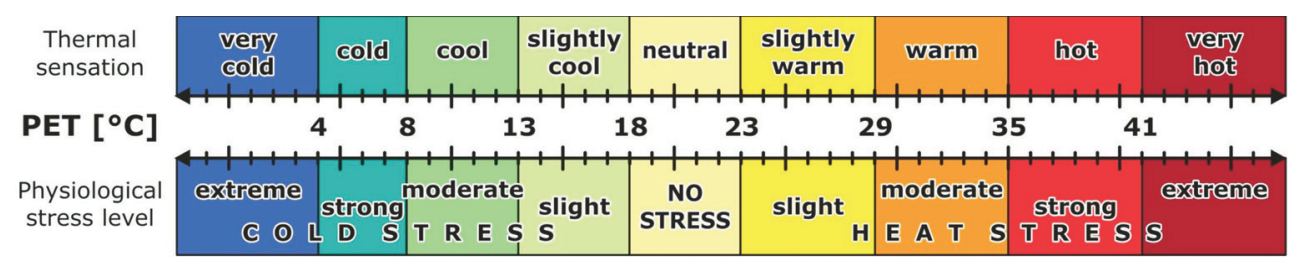

Fig. 1. The original threshold values of the PET index reflecting the thermal sensation categories and the level of physiological stress

H. 1996; Matzarakis, A. et al. 1999). However, adopting the preset threshold values regardless of the geographical location raises the question of the result's relevance regarding the thermal perception of local inhabitants.

Indeed, numerous studies found considerable differences between the actual thermal perception of people and the predicted evaluation based on the well-known objective indices (e.g. Lin, T.-P. and Matzarakis, A. 2008; KÁNTOR, N. et al. 2012a; YıN, J.F. et al. 2012; KRÜGER, E.L. et al. 2013; LAI, D. et al. 2014; Tung, C.-H. et al. 2014). Several papers reported that those thermal conditions at which people feel generally neutral depend on the geographical location and even on the time of the year (e.g. Nikolopoulou, M. and Lykoudis, S. 2006; Hwang, R.-L. and Lin, T.-P. 2007; Lin, T.-P. 2009; Lin, T.-P. et al. 2011; KÁNTOR, N. et al. 2012b; LindNER-CENDrowsKa, K. 2013; Yahia, M.W. and Johansson, E. 2013; YanG, W. et al. 2013a,b; Pearlmutter, D. et al. 2014; Chen, L. et al. 2015; Zeng, Y. and Dong, L. 2015). These results prove that living under various background climates lead to different degree of thermal adaptation in people, and even in the case of the same population, there are seasonal differences in the subjective evaluation.

Hungarian studies contributed also to this extensive research area and revealed obvious seasonal differences in the subjective thermal perception and preference patterns of local people (Kántor, N. et al. 2012a; Kovács, A. et al. 2015). Personal differences, time of the day (Pearlmutter, D. et al. 2014) and outdoor or semi-outdoor nature of the physical environment (HwAng, R.-L. and Lin, T.-P. 2007) were also investigated as affecting factors. However, to date, no studies have examined the influence of solar exposure on the subjective assessment of thermal environment. Therefore the present study aims to reveal these differences using the data of a long-term Hungarian outdoor thermal comfort (OTC) project. The main targets of this paper are set as follows:

1. Determining exposure-dependent differences in the subjective thermal sensation and thermal preference patterns in different seasons.

2. Specifying the so-called neutral and preferred temperature values of Hungarians according to season and solar exposure.

\section{Methods}

\section{The city of Szeged}

Building on the experiences of earlier investigations a long-term OTC project was conducted in the city of Szeged (Hungary) $\left(46^{\circ} 15^{\prime} \mathrm{N}\right.$, $\left.20^{\circ} 09^{\prime} \mathrm{E}\right)$. Szeged is the regional centre of the Southern Hungarian Great Plain with an urbanized area of about $50 \mathrm{~km}^{2}$. The city offers ideal study areas for urban climate and human bio-meteorological investigations (e.g. UnGER, J. 1996; Gulyás, Á. et al. 2006, 2009) because it is spread on a flat area without considerable topographical differences (78-85 m a.s.l.) which allows small-scale meteorological results to be generalized. Land-use types vary from the densely built-up inner city to the detached housing suburban areas, allowing the development of several local climate zone types (UNGER, J. et al. 2014). 
Szeged has warm temperate climate with uniform annual distribution of precipitation. The yearly amount of precipitation is low $(489 \mathrm{~mm})$, while the sunshine duration is high (1978 hours). The annual temperature is $10.6{ }^{\circ} \mathrm{C}$. July and August are the hottest months and January is the coldest time of the year. The daily maximum temperature is generally above $10^{\circ} \mathrm{C}$ from March to October, therefore these eight months are more suitable for outdoor activities. On the contrary, the period from November to February is cold when the monthly amount of sunshine remains below 100 hours (HMS 2015).

Being already one of the warmest cities in Hungary, the urban climate of Szeged is expected to be affected more intensively by the predicted warming tendencies in the Carpathian Basin (Pongrácz, R. et al. 2013). Moreover, Szeged is the third most populated city in the country with more than 170,000 permanent residents. All of these attributes make it very interesting from the viewpoint of OTC investigations.

\section{Outdoor thermal comfort surveys in Szeged}

Generally, OTC surveys consist of on-site human bio-meteorological measurements as well as transverse questionnaire surveys when great numbers of people are inquired about their subjective assessments regarding the actual thermal environment (CHEN, L. and NG, E. 2012; Rupp, R.F. et al. 2015). The Hungarian OTC measurements were carried out in 2011, 2012 and 2015. The investigations took place on six recreational areas, including popular urban squares, parks, playgrounds, and pedestrian zones (Figure 2). Two of the investigated squares (Szent István square and Dugonics square) received an Award of excellence for complete reconstruction from the Hungarian Society for Urban Planning. All survey sites are in the urbanized region of Szeged, allowing large number of visitors attending on them. The study areas can be characterized with a variety of landscapedesign solutions, materials, orientations, vegetation cover, etc. For that reason, a wide range of small-scale human bio-meteorological conditions may be expected on them.

With respect to outdoor activity, summer and the two transient seasons are of particular importance in Hungary. Accordingly, the OTC investigations covered the period from the end of March to the end of October, resulting, altogether, in 78 measurement days (Table 1). The data collection lasted from 10 a.m. to 6 p.m. except for those days when significant precipitation events interrupted the measurements.

\section{Micrometeorological measurements}

Two special human bio-meteorological stations were used to collect all important atmospheric variables that influence human thermal sensation. The stations were placed simultaneously at two significantly different sites of the same study area; typically in sunny and shaded (shaded by tree or building) position. Depending on the specific design of the study areas, the stations were placed sometimes on grassy surface, while other times on different types of artificial ground cover like asphalt pavement, red-coloured paving stones and light-coloured gravel (Figure 3).

The stations recorded one-minute averages of all meteorological variables. Air temperature $\left(T_{0}\right)$, relative humidity $(R H)$ and wind speed $(v)$ were measured by a WXT520 Vaisala weather transmitter in the case of both stations (Figure 3). Rotatable net radiometers were used to monitor the 3D radiant environment, i.e. to record short-wave and long-wave radiation flux densities from six perpendicular directions $\left(K_{i}\right.$ and $L_{i}$ $\left[\mathrm{W} / \mathrm{m}^{2}\right]$, i: up, down, East, West, South, North). One of the stations was equipped with CNR1, and the other with CNR4 type Kipp \& Zonen net radiometer. By means of telescopic tripods the sensors were placed at a height of 1.1-1.2 m above ground level which is suitable for OTC investigations (MAYER, H. et al. 2008).

Normally, the arm of the net radiometer points to the South. In this position the two pyranometers and two pyrgeometers faces 


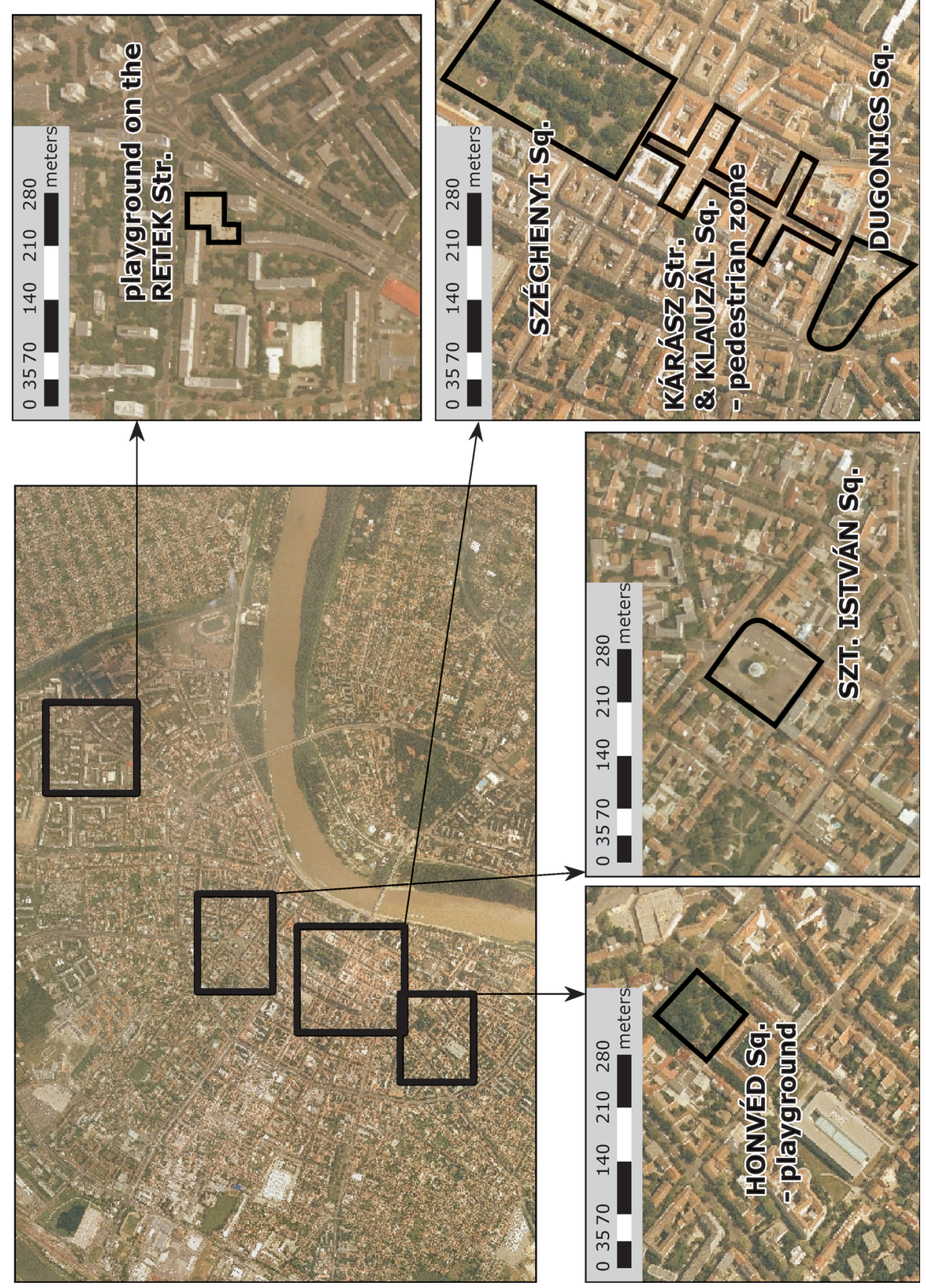


Table 1. Seasonal distribution of OTC measurement days in Szeged

\begin{tabular}{|c|c|c|c|c|c|c|c|}
\hline \multicolumn{3}{|c|}{ Spring (26 days) } & \multicolumn{3}{|c|}{ Summer (28 days) } & \multicolumn{2}{|c|}{ Autumn (24 days) } \\
\hline March & April & May & June & July & August & September & October \\
\hline 29.03 .2011 & 12.04 .2011 & 03.05 .2011 & 22.06 .2011 & 04.07.2011 & 03.08.2011 & 12.09.2011 & 03.10 .2011 \\
\hline 30.03 .2011 & 13.04.2011 & 04.05 .2011 & 07.06 .2012 & 08.07.2011 & 04.08.2011 & 13.09.2011 & 04.10 .2011 \\
\hline 26.03.2012 & 19.04.2011 & 10.05 .2011 & 08.06.2012 & 12.07.2011 & 22.08.2011 & 19.09.2011 & 10.10.2011 \\
\hline 27.03.2012 & 20.04.2011 & 11.05 .2011 & 21.06.2012 & 02.07.2012 & 23.08.2011 & 26.09.2011 & 17.10 .2011 \\
\hline- & 26.04 .2011 & 08.05.2012 & 25.06 .2012 & 05.07.2012 & 02.08.2012 & 27.09.2011 & 18.10.2011 \\
\hline- & 27.04.2011 & 15.05.2012 & 08.06.2015 & 06.07.2012 & 27.08.2012 & 17.09.2012 & 25.10.2011 \\
\hline- & 02.04 .2012 & 16.05 .2012 & 15.06.2015 & 09.07.2012 & 28.08.2012 & 18.09.2012 & 01.10 .2012 \\
\hline- & 03.04 .2012 & 08.05.2015 & 17.06.2015 & 10.07.2012 & - & 19.09.2012 & 03.10.2012 \\
\hline- & 16.04 .2012 & 13.05 .2015 & 18.06.2015 & 19.07.2012 & - & 21.09.2012 & 05.10 .2012 \\
\hline- & 23.04 .2012 & 19.05 .2015 & - & 20.07.2012 & - & 24.09.2012 & 08.10 .2012 \\
\hline- & 24.04 .2012 & 20.05.2015 & - & 23.07.2012 & - & 26.09.2012 & 10.10.2012 \\
\hline- & - & - & - & 24.07.2012 & - & - & 17.10 .2012 \\
\hline- & - & - & - & - & - & - & 19.10.2012 \\
\hline
\end{tabular}

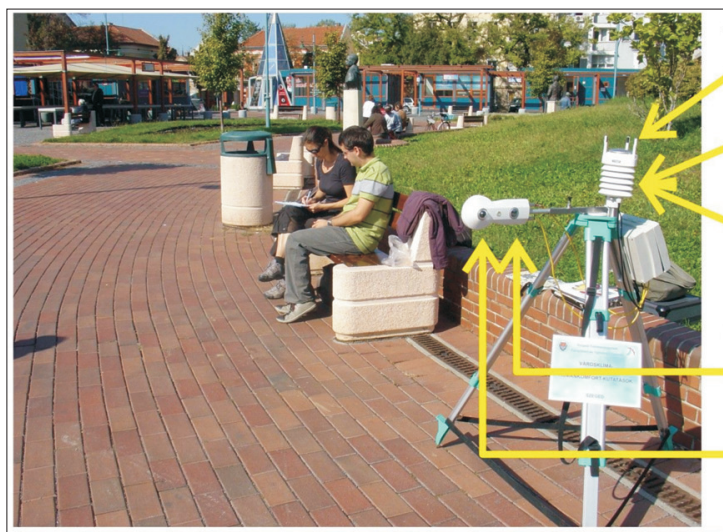

WXT 520, Vaisala

wind velocity

$v[\mathrm{~m} / \mathrm{s}] \pm 0.3^{\circ} \mathrm{C}$ at $20^{\circ} \mathrm{C}, \pm 0.25^{\circ} \mathrm{C}$ at $0^{\circ} \mathrm{C}$ air temperature

$\mathrm{Ta}\left[{ }^{\circ} \mathrm{C}\right] \pm 3 \%$ or $\pm 0.3 \mathrm{~m} / \mathrm{s}$ (the greater)

reative humidity

$\mathrm{RH}[\%] \pm 3 \%$ at $0-90 \%, \pm 5 \%$ at $90-100 \%$

\section{rotatable net radiometer, Kipp \& Zonen}

- long-wave radiation flux densities $\mathrm{Li}_{i}\left[\mathrm{~W} / \mathrm{m}^{2}\right]-\mathrm{L}_{\mathrm{u}}, \mathrm{L}_{\mathrm{d}}, \mathrm{L}_{\mathrm{e}}, \mathrm{L}_{\mathrm{W}}, \mathrm{L}_{\mathrm{s}}, \mathrm{L}_{n}$

short-wave radiation flux densities $\mathrm{K}_{\mathrm{i}}\left[\mathrm{W} / \mathrm{m}^{2}\right]-\mathrm{K}_{\mathrm{u}}, \mathrm{K}_{\mathrm{d}}, \mathrm{K}_{\mathrm{e}}, \mathrm{K}_{\mathrm{W}}, \mathrm{K}_{\mathrm{s}}, \mathrm{K}_{\mathrm{n}}$
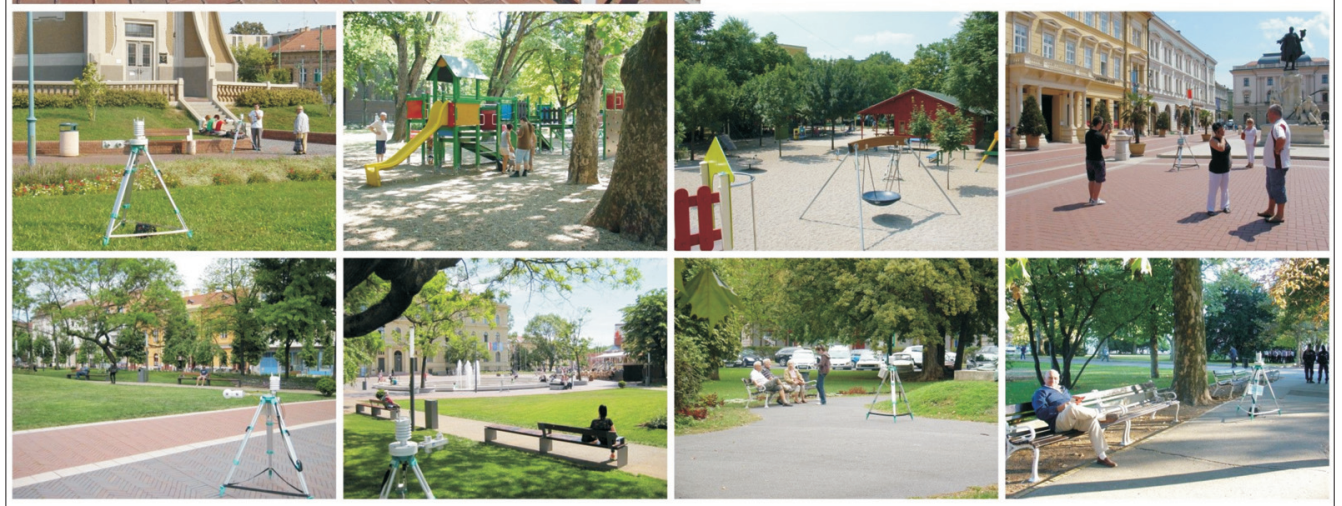

Fig. 3. Human bio-meteorological measurements and questionnaire surveys on popular recreational areas of Szeged. (Accuracy of measured parameters are also indicated). 
upward and downward, allowing the measurement of $K_{i}$ and $L_{i}$ separately from the upper and lower hemisphere $\left(K_{u^{\prime}} K_{d^{\prime}} L_{u^{\prime}} L_{\mathrm{d}}\right)$. After 3minute measurement in this position, the net radio-meters were rotated manually into the second position when the sensors faced to East and West $\left(K_{e^{\prime}} K_{w^{\prime}} L_{e^{\prime}} L_{w}\right)$. Again, after 3-minute measurement the arms were turned with $90^{\circ}$ to measure from South and North $\left(K_{s^{\prime}} K_{n^{\prime}} L_{s^{\prime}}\right.$ $\left.L_{n}\right)$. Considering the 10 a.m. -6 p.m. measurement interval, this procedure required 160 rotations per day in the case of both stations. Taking into account the response time of the sensors as well as the time delay due to the manual rotation, all $K_{i}$ and $L_{i}$ were deleted that were recorded first time after the rotations.

\section{Index calculation}

Mean radiant temperature $\left(T_{m r t}\left[{ }^{\circ} \mathrm{C}\right]\right)$ is a parameter with primary importance in the field of human bio-meteorology and OTC surveys. It combines all long-wave and short-wave radiant flux densities into a single value with ${ }^{\circ} \mathrm{C}$-dimension. $T_{m r t}$ is defined as the uniform temperature of an imaginary black body-radiating surrounding, which results in the same radiant heat exchange for the human body inside this hypothetical environment as the complex 3D-radiant environment in the reality (Höppe, P. 1992; Kántor, N. and Unger, J. 2011). $T_{m r t}$ is usually calculated for a standardized standing person. In the case of this study, $T_{m r t}$ was determined based on six $K_{i}$ and six $\mathrm{L}_{\mathrm{i}}$ flux densities, which were obtained from three consecutive stands of the net radiometer:

$$
T_{m r t}=\left(\frac{\sum_{i=1}^{6} W_{i} \cdot\left(a_{k} \cdot K_{i}+a_{l} \cdot L_{i}\right)}{a_{l} \cdot \sigma}\right)^{\frac{1}{4}}-273.15
$$

where $a_{k}$ and $a_{l}$ are absorption coefficients of the clothed human body in the short- and long-wave radiation domain (assumed to be 0.7 and 0.97 , respectively), $\sigma$ is the Stefan-Boltzmann constant $\left(5.67 \cdot 10^{-8} \mathrm{~W} / \mathrm{m}^{2} \mathrm{~K}^{4}\right)$ and $W_{i}$ is a direction-dependent weighting factor. Assuming standing reference subject, $W_{i}$ is 0.06 for vertical and 0.22 for horizontal directions (Höppe, P. 1992).
PET index was selected for the purpose of this study to describe the thermal environment along with the possible thermal sensation and degree of physiological stress (Figure 1). PET is regarded to be one of the most comprehensive human bio-meteorological indices and it has been widely used for different OTC studies all around the world (e.g. Gulyás, Á. et al. 2006; Lin, T.-P. 2009; KáNTOR, N. et al. 2012a; YAHIA, M.W. Johansson, E. 2013; Pearlmutter, D. et al. 2014; Kovács, A. et al. 2015; ZENG, Y. and Dong, L. 2015). PET calculations were performed with the RayMan software (MATZARAKIs, A. et al. 2010) by using the formerly obtained $T_{m r t}$ values and the directly measured $T_{a^{\prime}} R H, v$ values. The evaluation by PET (Figure 1) always refers to a standardized subject (a 'typical' 35 years old Central European man performing light activity and wearing light business suit) representing a large group of people (Höppe, P. 1999).

\section{Recording subjective assessment of thermal environment}

The assessment of thermal conditions is highly subjective, meaning that different individuals may evaluate the same thermal environment differently (MAYER, H. 2008). In order to reveal these patterns, structured interviews were carried out with thousands of people spending their time in the study areas during the human-meteorological measurements. People who walked, stood or sat near to the stations were invited to fill an OTC questionnaire which could be finished within five minutes (Figure 3). Similarly to many international examples (e.g. NiкоLоpoulou, M. and Lyкоudis, S. 2006; HwAnG, R.-L. and Lin, T.-P. 2007; Lin, T.-P. 2009; KRÜGER, E.L. et al. 2013; YANG, W. et al. 2013a,b; Pearlmutter, D. et al. 2014; Chen, L. et al. 2015; Zeng, Y. and Dong, L. 2015), the questionnaire consisted of more question blocks regarding personal factors, area usage, behavioral reactions, evaluation of the area and subjective assessment of the thermal environment (KánTOR, N. et al. 2012a). 
This paper focuses on the subjective thermal sensation and thermal preference. Thermal Sensation Votes (TSV) were collected by means of a semantic differential scale with 9 main ordered categories: very cold $(-4)$, cold (-3), cool (-2), slightly cool (-1), neutral (0), slightly warm (1), warm (2), hot (3), very hot (4). Selection of intermediate options was also possible. Thermal Preference Votes were recorded by answering the question 'Would you like any changes in the actual thermal conditions to feel (more) comfortable?' In this case, people could choose from three options: want cooler (-1), want no change (0), want warmer $(+1)$.

From the collected personal information this paper focuses on the solar exposure of subjects - whether they stayed in the sun, or in the shade. Sometimes the ascertainment of the position was not possible because clouds reduced the intensity of global radiation, thus made impossible to distinguish shaded and sunny areas. These questionnaires were excluded from the analyses.

Additionally, many samples were removed due to missing meteorological data (failure in the recordings of any micrometeorological parameters which hindered the calculation of PET index).

\section{Analysis methods}

Regression analysis was performed for comparing subjective thermal sensation (and thermal preference) patterns and specifying neutral (and preferred) temperatures according to the investigated seasons and solar exposure. Besides, probit model was adopted to analyse the thermal preferences of Hungarians among different circumstances. These main analyses were supplemented with simple descriptive statistics. The analyses were performed within the PASW Statistics software, and some of the artworks were created within MS Excel.

\section{Results and discussion}

\section{Thermal sensation according to seasons and} solar exposure

6,764 questionnaires were obtained during the field surveys, but only 4,700 subjects were selected for the purpose of this study; only those who had valid PET index and solar exposure. All interviewees were Hungarian citizens, generally they reported about good health conditions and $2 / 3$ of them were female. The individuals' age varied between 5 to 95 years, and most of them belonged to the young age group (14 to 30 years).

People selected generally from the main thermal sensation votes (Figure 4). Nevertheless, more than $20 \%$ of the questioned individuals selected intermediates (votes of 1.5 and 2.5 occurred most frequently). The most frequent vote was slightly warm (1) in both transient seasons. In summer however, in accordance with the warmer thermal
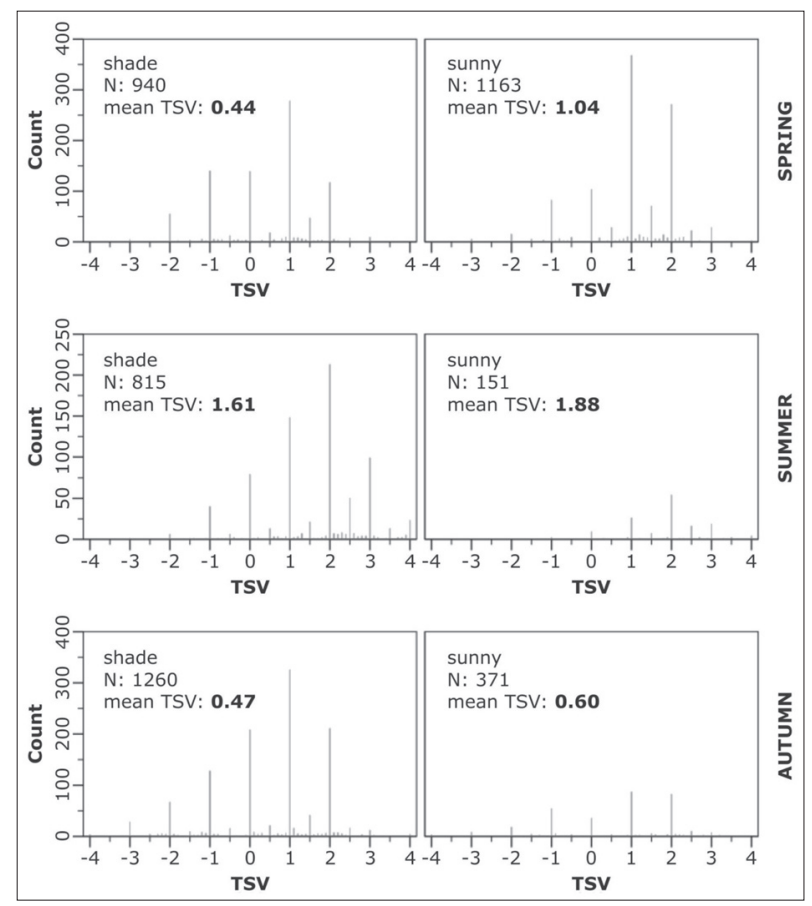

Fig. 4. Distribution of TSV according to seasons and subjects' solar exposure 
conditions, people reported most frequently warm (2) thermal sensation. In each season, mean TSV values were lower if subjects stayed in the 'shade'. The greatest difference between the two exposure groups was found in spring (Figure 4).

\section{Neutral temperature and neutral PET zone}

Neutral temperature ( $n P E T)$ refers to those thermal conditions at which people feel neither cool, nor warm, i.e. which are perceived as neutral. Several studies determined $n P E T$ by regression analysis between TSV and PET (e.g. Lin, T.-P. 2009; KánTor, N. et al. 2012a,b; YANG, W. et al. 2012b; KRÜGER, E.L. et al. 2013; YAHIA, M.W. and Johansson, E. 2013; Kovács, A. et al. 2015). Since thermal sensation varies greatly among subjects even in the same thermal conditions (i.e. at the same PET value), mean thermal sensation votes (MTSV) were calculated according to $1{ }^{\circ} \mathrm{C}$ wide $P E T$ intervals. Considerably different thermal perception patterns were revealed among the investigated groups by plotting mean TSV values against PET index, and weighting them with the case numbers per PET bin (Figure 5).

Quadratic regression fit the TSV-PET data pairs well with considerable statistical significance (Table 2). According to the determination coefficients $\left(R^{2}\right)$ at least $92 \%$ of the variability in Hungarians' subjective thermal sensation can be explained by the PET index in every season if the subjects stay in shaded position. The worst $R^{2}$ value was found in the summertime 'sunny' group; probably due to the small sample size $(N=151)$.

Neutral temperature ( $n P E T)$ can be determined by solving the regression equation for $T S V=0$, or reading its value from the regression chart. The fitted quadratic functions intersect the TSV $=0$ line at different PET values, indicating sometimes considerably different $n P E T$ (Figure 5). Substituting -0.5 and 0.5 into the quadratic equations assign the lower and upper PET thresholds of the neutral category. Worth noting that for the 'sunny' group in summer the values of $n P E T$ and the lower boundary of neutrality could be determined only by extrapolation, i.e. outside from the covered PET range (Figure 5).

\section{Preferred temperature and preferred PET zone}

Two analysis techniques were adopted aiming to allocate the preferred thermal conditions in different seasons and different exposure groups. First, the above presented regression procedure was repeated for thermal preference votes (Kovács, A. et al. 2015; Table 3). Compared to the case of TSV, the obtained $R^{2}$ values were lower in this case, probably due to people had only three preference options to choose. However, the significance level was 0.000 in every group and the quadratic functions fitted the TPV-PET data pairs fairly well. Preferred temperature ( $p P E T)$, as well as the boundaries of the preferred PET zone were calculated by substituting $0,0.125$ and -0.125 into the quadratic equations. The obtained results will be demonstrated later.

The other way of $P P E T$ determination is based on probit model (BALLANTYNe, E.R. et al. 1977). Generally, probit analysis is used to investigate many kinds of dichotomous response variables in a variety of research fields. In this study, two binomial response variables were investigated as a function of $P E T$ : the relative frequency of $T P V>0$ (want warmer) and $T P V<0$ (want cooler) votes per PET bin. $1{ }^{\circ} \mathrm{C}$ wide PET intervals were utilized for both models. The occurrence probability of the mentioned preference votes depends on PET according to a sigmoid function (a mathematical function having an 'S' shape), and with the increment of $P E T$ the probability of TPV $>0$ votes decreases, while the probability of $T P V<0$ votes increases (Figure 6). Pearson goodness of fit test (building on $\chi^{2}$ statistics) was utilized to check the obtained probit models (Table 4). The significance level was generally below 0.150 , indicating that the fit was sufficient in most of the cases.

Researchers from East Asia assumed that the intersection point of the fitted probit models $T P V<0$ and $T P V>0$ indicates the preferred temperature (HwANG, R.-L. and LIN, T.-P. 2007; 

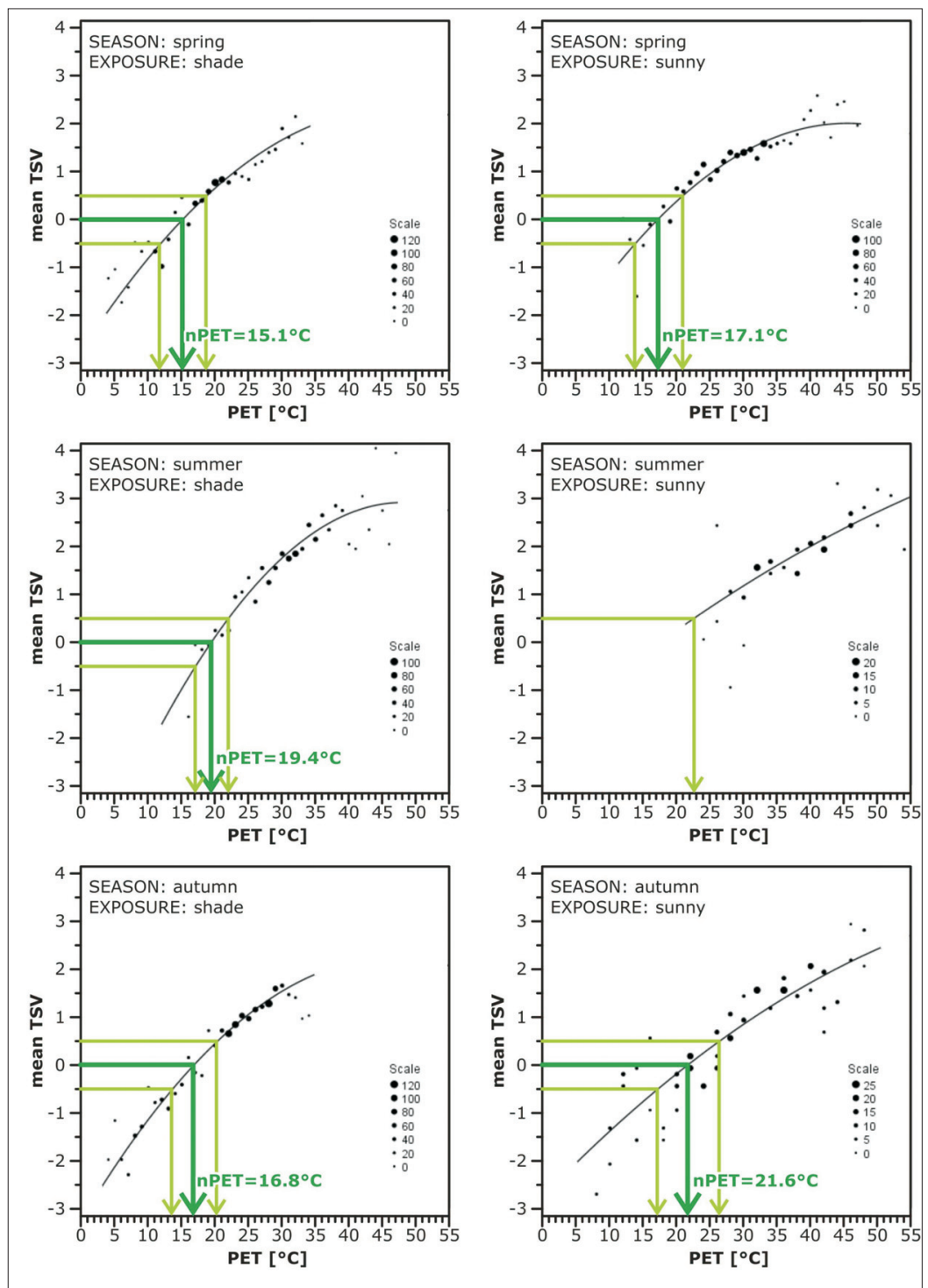

Fig. 5. Determination of neutral temperature $(n P E T)$ and neutral PET zone according to seasons and exposure groups

Table 2. Quadratic regression between 'weighted mean TSV' and PET

\begin{tabular}{l|l|r|r|r|c}
\hline \multicolumn{2}{c|}{ Conditions } & \multicolumn{1}{c|}{$\mathrm{N}$} & $\mathrm{R}^{2}$ & Sig. & Equation \\
\hline \multirow{2}{*}{ Spring } & shade & 940 & 0.919 & 0.000 & $-2.28 \cdot 10^{-3} \cdot \mathrm{PET}^{2}+0.215 \cdot \mathrm{PET}-2.715$ \\
& sunny & 1,163 & 0.899 & 0.000 & $-2.50 \cdot 10^{-3} \cdot \mathrm{PET}^{2}+0.227 \cdot \mathrm{PET}-3.152$ \\
\hline \multirow{2}{*}{ Summer } & shade & 815 & 0.928 & 0.000 & $-3.56 \cdot 10^{-3} \cdot \mathrm{PET}^{2}+0.342 \cdot \mathrm{PET}-5.294$ \\
& sunny & 151 & 0.645 & 0.000 & $-0.53 \cdot 10^{-3} \cdot \mathrm{PET}^{2}+0.119 \cdot \mathrm{PET}-1.921$ \\
\hline \multirow{2}{*}{ Autumn } & shade & 1,260 & 0.967 & 0.000 & $-2.50 \cdot 10^{-3} \cdot \mathrm{PET}^{2}+0.234 \cdot \mathrm{PET}-3.218$ \\
& sunny & 371 & 0.811 & 0.000 & $-0.83 \cdot 10^{-3} \cdot \mathrm{PET}^{2}+0.144 \cdot \mathrm{PET}-2.735$ \\
\hline
\end{tabular}


Table 3. Quadratic regression between 'weighted mean TPV' and PET

\begin{tabular}{l|l|r|r|r|c}
\hline \multicolumn{2}{c|}{ Conditions } & \multicolumn{1}{c|}{$\mathrm{N}$} & $\mathrm{R}^{2}$ & Sig. & Equation \\
\hline \multirow{2}{*}{ Spring } & shade & 940 & 0.935 & 0.000 & $-1.77 \cdot 10^{-3} \cdot \mathrm{PET}^{2}+0.015 \cdot \mathrm{PET}^{2}+0.893$ \\
& sunny & 1,163 & 0.827 & 0.000 & $-0.52 \cdot 10^{-3} \cdot \mathrm{PET}^{2}-0.010 \cdot \mathrm{PET}+1.033$ \\
\hline \multirow{2}{*}{ Summer } & shade & 815 & 0.912 & 0.000 & $2.90 \cdot 10^{-3} \cdot \mathrm{PET}^{2}-0.235 \cdot \mathrm{PET}+3.918$ \\
& sunny & 151 & 0.593 & 0.000 & $-0.87 \cdot 10^{-3} \cdot \mathrm{PET}^{2}+0.019 \cdot \mathrm{PET}+0.288$ \\
\hline \multirow{2}{*}{ Autumn } & shade & 1,260 & 0.925 & 0.000 & $-0.04 \cdot 10^{-3} \cdot \mathrm{PET}^{2}-0.052 \cdot \mathrm{PET}^{2}+1.159$ \\
& sunny & 371 & 0.755 & 0.000 & $-0.51 \cdot 10^{-3} \cdot \mathrm{PET}^{2}-0.004 \cdot \mathrm{PET}^{+0.645}$ \\
\hline
\end{tabular}

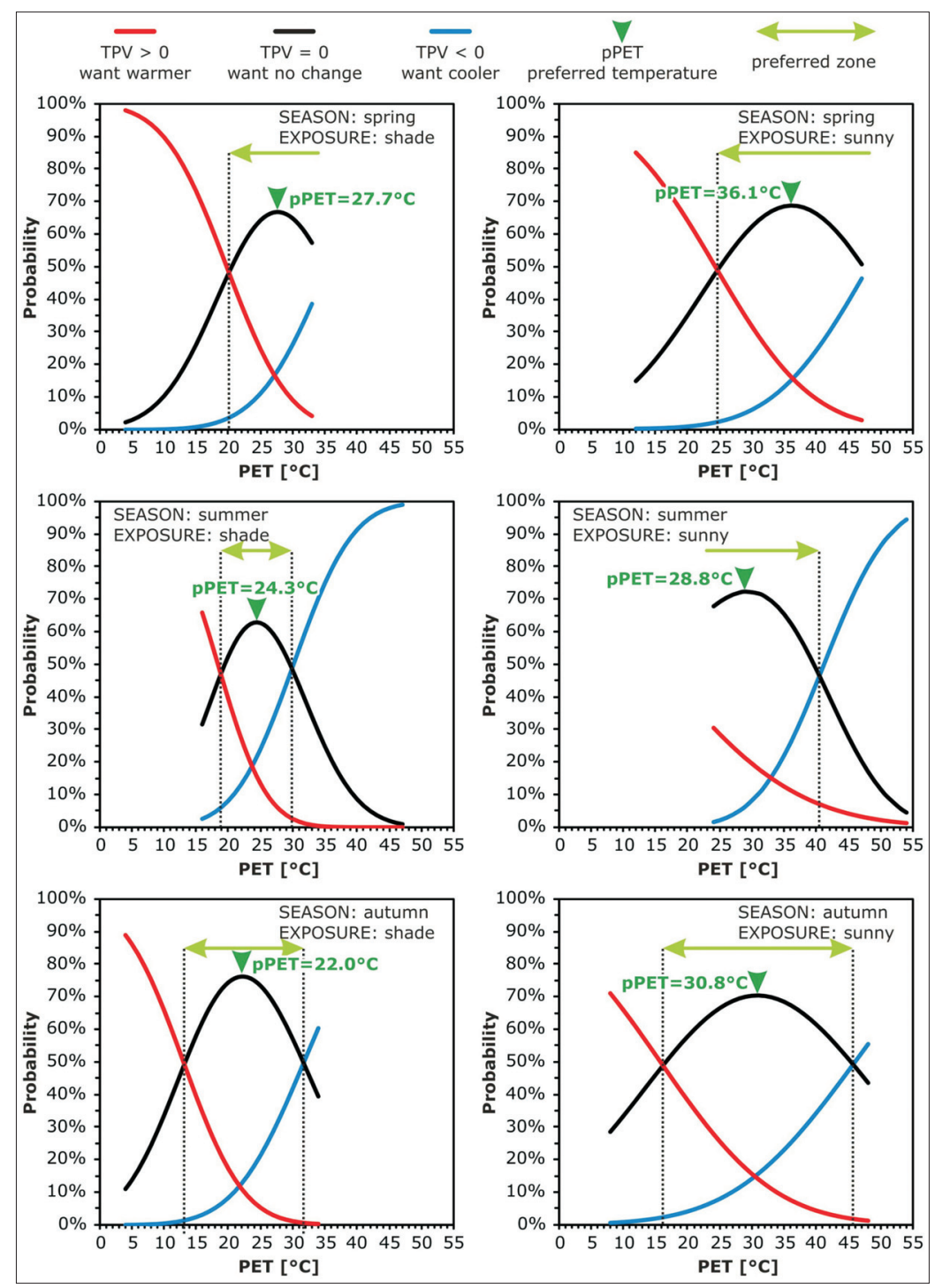

Fig. 6. Determination of preferred temperature $(p P E T)$ and thermal preference zone based on probit technique 
Table 4. Goodness of fit of the probit models

\begin{tabular}{|c|c|c|c|c|c|c|}
\hline \multirow{2}{*}{\multicolumn{2}{|c|}{ Conditions }} & \multirow{3}{*}{$\begin{array}{c}\text { Number of } \\
\text { PET bins } \\
30 \\
35\end{array}$} & \multicolumn{2}{|c|}{ model TPV $<0$} & \multicolumn{2}{|c|}{ model TPV $>0$} \\
\hline & & & $\gamma^{2}$ & $\mathrm{Sig}$ & $\gamma^{2}$ & $\mathrm{Sig}$ \\
\hline Spring & $\begin{array}{l}\text { shade } \\
\text { sunny }\end{array}$ & & $\begin{array}{l}51.618 \\
43.645\end{array}$ & $\begin{array}{l}0.004 \\
0.102\end{array}$ & $\begin{array}{l}31.534 \\
48.044\end{array}$ & $\begin{array}{l}0.294 \\
0.044\end{array}$ \\
\hline Summer & $\begin{array}{l}\text { shade } \\
\text { sunny }\end{array}$ & $\begin{array}{l}32 \\
29\end{array}$ & $\begin{array}{l}89.711 \\
30.301 \\
\end{array}$ & $\begin{array}{l}0.000 \\
0.301\end{array}$ & $\begin{array}{r}13,894.862 \\
34.233 \\
\end{array}$ & $\begin{array}{l}0.000 \\
0.159\end{array}$ \\
\hline Autumn & $\begin{array}{l}\text { shade } \\
\text { sunny }\end{array}$ & $\begin{array}{l}31 \\
41\end{array}$ & $\begin{array}{l}57.067 \\
53.028\end{array}$ & $\begin{array}{l}0.001 \\
0.066\end{array}$ & $\begin{array}{r}350.176 \\
40.031\end{array}$ & $\begin{array}{l}0.000 \\
0.424\end{array}$ \\
\hline
\end{tabular}

Lin, T.-P. 2009; Lin, T.-P. et al. 2011; YANG, W. et al. 2013a,b). However, $T P V<0$ and $T P V>0$ curves intersect each other always below $50 \%$ level of probability, and considering a vertical axis, the two transition curves are usually not symmetrical to each other (Figure 6). That is, the rate of decline in the probability of 'want warmer' votes does not equal generally to the rate of incline in the probability of 'want cooler' votes. Therefore the intersection point does not necessarily coincide with the maximum probability of 'want no change' votes. Consequently, it seemed reasonable to depict the probability of TPV $=0$ votes (calculated by substracting the probabilities of $T P V<0$ and $T P V>0$ from $100 \%$ ) against the PET index and assign $p P E T$ where this curve reaches its maximum. Besides, preferred PET zone could be defined on those PET range where the occurrence probability of $T P V=0$ vote exceeds the probability of the other votes (Figure 6).

\section{Summary of the results}

Figure 7 offers a graphical summary about the $p P E T$ values obtained through the different analysis approaches. The outcomes are very close to each other in almost every case. Moreover, the match is perfect in the cases of the sunny-spring, and the shade-autumn groups. The greatest difference $\left(3.5^{\circ} \mathrm{C}\right)$ was found in the sunny-summer group. Note that the probit-fit was less significant ( $\operatorname{sig}=$ 0.301 for $T P V<0$ and 0.159 for $T P V>0$ ) in this group, moreover, this group had the lowest $R^{2}(0.593)$ value in quadratic regression.

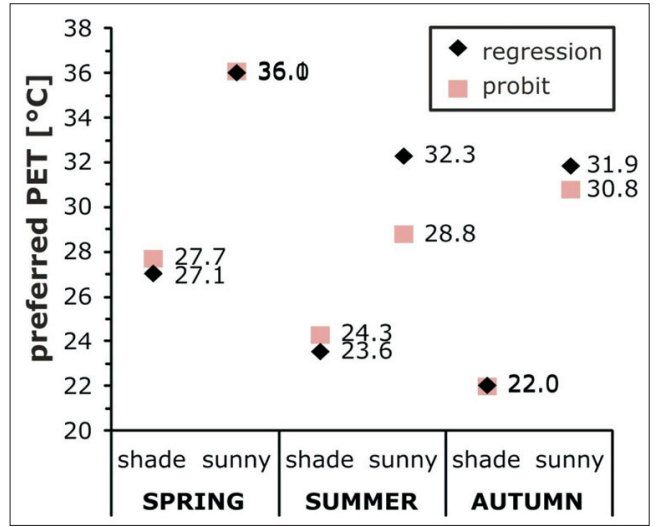

Fig. 7. Comparison of $p P E T$ values obtained through different analysis techniques

Figure 8 offers a graphical overview about the neutral and preferred thermal conditions (based on the results obtained through the regression technique). One can observe first of all the striking difference between the $n P E T$ and $p P E T$ values. Hungarians' $n P E T$ values ranged from $15.1{ }^{\circ} \mathrm{C}$ (spring-shade) to $21.6^{\circ} \mathrm{C}$ (autumn-sunny), thereby falling into the original PET-zones of 'slight cold stress' and 'no thermal stress'. On the contrary, $p P E T$ values scattered from the 'no thermal stress' to 'strong heat stress' categories. The lowest pPET $\left(22^{\circ} \mathrm{C}\right)$ occurred in the autumn-shade group and the highest $\left(36^{\circ} \mathrm{C}\right)$ in the spring-sunny group.

The second most important feature is the remarkable difference between the sunny and shaded groups (Figure 8). Indeed, sunny $n P E T$ and $P P E T$ values were always higher than the corresponding shaded values. In terms of $n P E T$ the difference was only $2{ }^{\circ} \mathrm{C}$ in spring, 


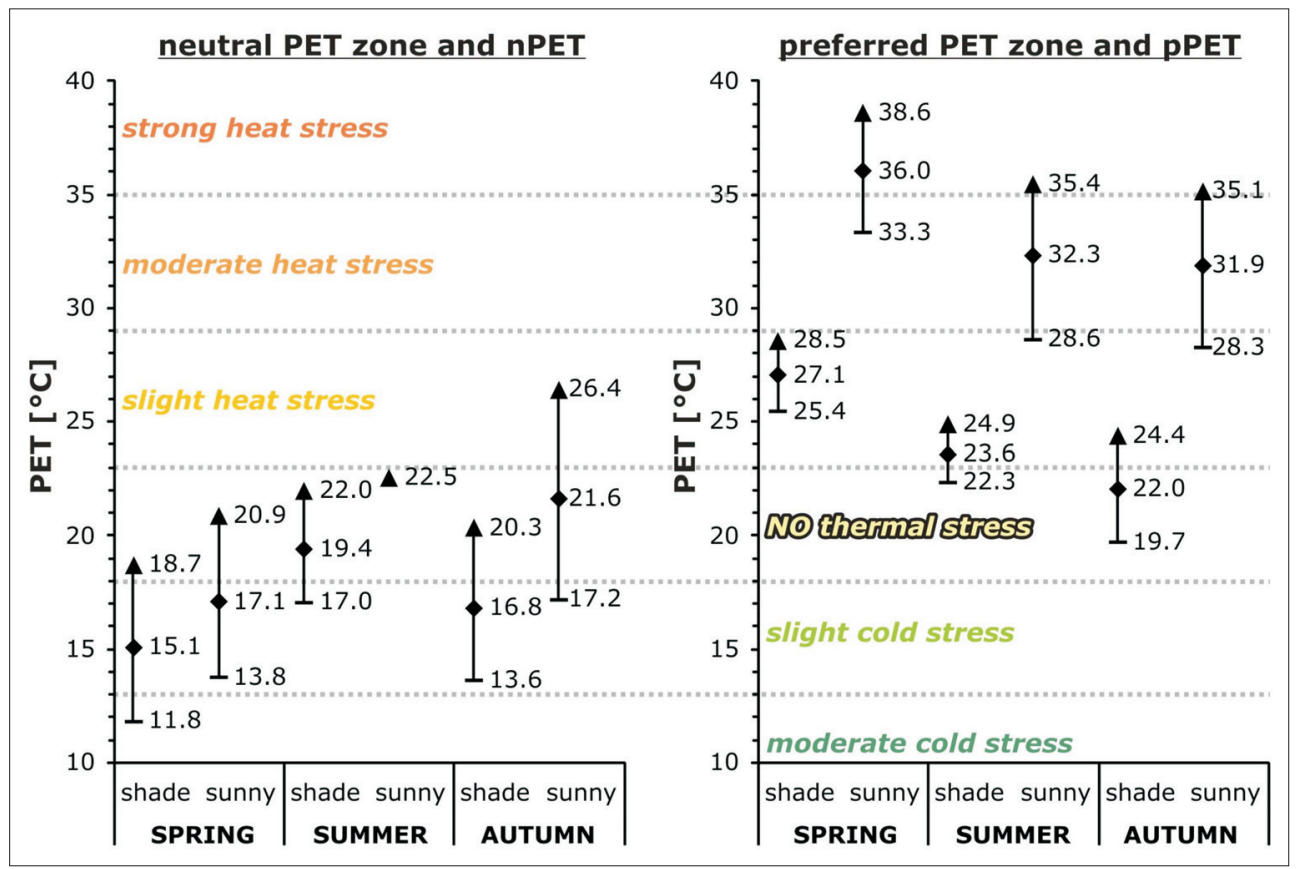

Fig. 8. Thermal conditions assessed as 'neutral' and 'preferred' by Hungarians according to their solar exposure in different seasons (all results are based on regression technique; level of thermal stress is indicated according to the original PET scale)

while it was almost $5{ }^{\circ} \mathrm{C}$ in autumn. The differences in $P P E T$ values were even greater: they were close to 10 degrees in every season.

Finally, different seasonal order can be observed in $n P E T$ and $p P E T$ values. (Merely the shaded exposure group is discussed here, because the sunny results are more uncertain due to the lower sample size.) The $n P E T$ values follow the increasing order of spring, autumn and summer (Figure 8), which corresponds both to the general seasonal background temperature differences, both to the differences in the recorded actual thermal conditions. This seasonal pattern proves that Hungarian people adapt themselves to the seasonally different climate conditions. In summer they perceive neutral between 17 ${ }^{\circ} \mathrm{C}$ and $22{ }^{\circ} \mathrm{C}$ (with a neutral temperature of $19.4^{\circ} \mathrm{C}$ ), while in the cooler transient seasons they feel neutral at lower PET values which can be assessed even as slight cool stress. Regarding the preferred thermal conditions, the seasonal order is different: $p P E T$ is around $22^{\circ} \mathrm{C}$ in autumn and summer, while it is above $27^{\circ} \mathrm{C}$ in spring. (The sunny-springtime value is even higher: it is $36^{\circ} \mathrm{C}$.)

The highest $p P E T$ in springtime, as well as the greatest difference between the $n P E T$ and PPET values in spring may be explained as follows. After the cold and dark winter period Hungarian people are looking for any environmental opportunities to feel warm. Although they are adapted to cooler temperatures during winter, they wish for warmer thermal sensation, even if this behaviour connotes certain degree of heat stress. The longing for warmer thermal conditions make most people to expose them to the intense direct sunlight in springtime (see the great portion of subjects in the spring-sunny group; Figure 4), which may have serious consequences regarding their sensitive skin and sensitive thermoregulation system at the end of the long winter-period. 
Relevance of the research findings

Although PET and many other well-established indices are sufficiently and frequently used in the field of human-biometeorology for the objective assessment of the thermal environment, the outcomes of this study prove the importance of questionnaire-supported OTC investigations. Having knowledge about the subjective thermal assessment of local people allows explaining such 'illogical' outdoor behaviours which are reported by KáNTOR, N. and UnGER, J. (2010). By comparing the number of visitors and their outdoor behaviours in a small urban park in the transient seasons they revealed that in spite of the strong heat stress, most people tend to sit or lie in sunny places in springtime. At the same level of thermal stress in autumn, people rather choose shady places to spend their time outdoors (KÁNTOR, N. and UNGER, J. 2010).

This investigation demonstrated clear seasonal differences in neutral temperature and preferred temperature, similarly to previous studies (e.g. Spagnolo, J. and De Dear, R. 2003; NiKolopoulou, M. and LyKoudis, S. 2006; Lin, T.-P. 2009). Additionally, this paper evinced that subjective thermal sensation may greatly differ from the original PET categorization system which was established for Central European people (MatzaraKis, A. and Mayer, H. 1996). Indeed, except the shady-summer group, the neutral zone of Hungarian people (Figure 8) was considerably wider than the original $5{ }^{\circ} \mathrm{C}$-wide zone $\left(18-23{ }^{\circ} \mathrm{C}\right.$; Figure 1) indicating greater tolerance against the changes of outdoor thermal environment. The width of the neutral zone exceeded $7^{\circ} \mathrm{C}$ in the transient seasons, being more than $9^{\circ} \mathrm{C}$ wide in the sunny-autumn group. This finding may be explained by the multifarious and changeable weather conditions in the transient seasons, which make people less sensitive against the variations of outdoor thermal conditions.

As most important achievement, this paper revealed that solar exposure has significant influence on the subjective evaluation of thermal conditions. This finding may have inter- national significance. As mentioned above, several studies reported about seasonal differences in neutral temperature without scrutinizing the role of exposure on the obtained results. However, people choose different positions in different seasons: seeking to expose them to direct sunlight after the cold and dark winter months, and stay in the shade during summer and the warm months of autumn. The different seasonal exposurepatterns mean that the neutral temperature reflects more the assessment of sun-exposed subjects in spring, and the assessment of people in the shade in summer and autumn. Thorough analysis of the seasonal neutral (and preferred) temperature values according to exposure-groups sheds more light on the real assessment patterns of local people, which explains better the seasonal differences in their outdoor behaviour.

Acknowledgement: The author would like to acknowledge Lilla Egerházi, Ágnes TAKÁcs and Attila Kovács for their valuable help in the course of field measurements or later in the period of data processing.

\section{REFERENCES}

Ballantyne, E.R., Hill, R.K. and Spencer, J.W. 1977. Probit analysis of thermal sensation assessments. International Journal of Biometeorology 21. 29-43.

Chen, L. and NG, E. 2012. Outdoor thermal comfort and outdoor activities: a review of research in the past decade. Cities 29. 118-125.

Chen, L., Wen, Y., Zhang, L. and XIAng, W.N. 2015. Studies of thermal comfort and space use in an urban park square in cool and cold seasons in Shanghai. Building and Environment 94. 644-653.

FröHLICH, D. and Matzarakis, A. 2013. Modelling of changes in thermal bioclimate: examples based on urban spaces in Freiburg, Germany. Theoretical and Applied Climatology 111. 547-558.

Gómez, F., Pérez Cueva, A., Valcuende, M. and MatzaraKis, A. 2013. Research on ecological design to enhance comfort in open spaces of a city (Valencia, Spain). Utility of the physiological equivalent temperature (PET). Ecological Engineering 57. 27-39.

Gulyás, Á., Matzarakis, A. and Unger, J. 2009. Differences in the thermal bioclimatic conditions on the urban and rural areas in a southern Hungarian city (Szeged). Berichte des Meteorologischen Institutes der Universität Freiburg 18. 229-234. 
Gulyás, Á., Unger, J. and Matzarakis, A. 2006. Assessment of the microclimatic and human comfort conditions in a complex urban environment: modelling and measurements. Building and Environment 41. 1713-1722.

HMS 2015. Climate characteristics of Szeged. http:// www.met.hu/eghajlat/magyarorszag_ eghajlata/ varosok_jellemzoi/Szeged/

Höppe, P. 1992. Ein neues Verfahren zur Bestimmung der mittleren Strahlungstemperatur im Freien. Wetter und Leben 44. 147-151.

Höppe, P. 1999. The physiological equivalent temperature - a universal index for the biometeorological assessment of the thermal environment. International Journal of Biometeorology 43. 71-75.

HwANG, R-L. and Lin, T-P. 2007. Thermal comfort requirements for occupants of semi-outdoor and outdoor environments in hot-humid regions. Architectural Science Review 50. 357-364.

Hwang, R-L., Lin, T-P. and Matzarakis, A. 2011. Seasonal effects of urban street shading on longterm outdoor thermal comfort. Building and Environment 46. 863-870.

IPCC 2014. Climate Change 2014: Synthesis Report, 2014. Contribution of Working Groups I, II and III to the Fifth Assessment Report of the Intergovernmental Panel on Climate Change (Core Writing Team, eds. PAchaurI, R.K. and Meyer, L.A.), Geneva, IPCC.

KÁNTOR, N. and Unger, J. 2010. Benefits and opportunities of adopting GIS in thermal comfort studies in resting places: An urban park as an example. Landscape and Urban Planning 98. 36-46.

KÁNTOR, N. and Unger, J. 2011. The most problematic variable in the course of human biometeorological comfort assessment - the mean radiant temperature. Central European Journal of Geosciences 3. 90-100.

Kántor, N., Égerházi, L.A. and Unger, J. 2012a. Subjective estimation of thermal environment in recreational urban spaces. Part 1: investigations in Szeged, Hungary. International Journal of Biometeorology 56. 1075-1088.

Kántor, N., Unger, J. and Gulyás, Á. 2012 b. Subjective estimations of thermal environment in recreational urban spaces - Part 2: international comparison. International Journal of Biometeorology 56. 1089-1101.

Kovács, A., Unger, J., Gál, C.V. and Kántor, N. 2015. Adjustment of the thermal component of two tourism climatological assessment tools using thermal perception and preference surveys from Hungary. Theoretical and Applied Climatology. Doi: 10.1007/s00704-015-1488-9.

Krüger, E.L., Drach, P., Emmanuel, R. and Corbella, O. 2013. Assessment of daytime outdoor comfort levels in and outside the urban area of Glasgow, UK. International Journal of Biometeorology 57. 521-533.
LaI, D., Guo, D., Hou, Y., Lin, C. and Chen, Q. 2014 Studies of outdoor thermal comfort in northern China. Building and Environment 77. 110-118.

LIN, T.-P. 2009. Thermal perception, adaptation and attendance in a public square in hot and humid regions. Building and Environment 44. 2017-2026.

Lin, T.-P. and Matzarakis, A. 2008. Tourism climate and thermal comfort in Sun Moon Lake, Taiwan. International Journal of Biometeorology 52. 281-290.

Lin, T.-P., De Dear, R. and Hwang. R.-L. 2011. Effect of thermal adaptation on seasonal outdoor thermal comfort. International Journal of Climatology 31. 302-312.

Lin, T.-P., Matzarakis, A. and Hwang, R.-L. 2010. Shading effect on long-term outdoor thermal comfort. Building and Environment 45. 213-221.

LindNER-CENDROWSKA, K. 2013. Assessment of bioclimatic conditions in cities for tourism and recreational purposes (a Warsaw case study). Geographia Polonica 86. 55-66.

Matzarakis, A. and Mayer, H. 1996. Another kind of environmental stress: thermal stress. WHO Newsletter 18. 7-10.

Matzarakis, A., Mayer, H. and Iziomon, M.G. 1999. Application of a universal thermal index: physiological equivalent temperature. International Journal of Biometeorology 43. 76-84.

Matzarakis, A., Rutz, F. and Mayer, H. 2010. Modelling radiation fluxes in simple and complex environments: basics of the RayMan model. International Journal of Biometeorology 54. 131-139.

Mayer, H., Holst, J., Dostal, P., Imbery, F. and Schindler, D. 2008. Human thermal comfort in summer within an urban street canyon in Central Europe. Meteorologische Zeitschrift 17. 241-250.

Müller, N., Kuttler, W. and Barlag, A.B. 2014. Counteracting urban climate change: adaptation measures and their effect on thermal comfort. Theoretical and Applied Climatology 115. 243-257.

Nikolopoulou, M. and Lyкoudis, S. 2006. Thermal comfort in outdoor urban spaces: Analysis across different European countries. Building and Environment 41. 1455-1470.

Pearlmutter, D., Jiao, D. and Garb, Y. 2014. The relationship between bioclimatic thermal stress and subjective thermal sensation in pedestrian spaces. International Journal of Biometeorology 58. 2111-2127.

Pongrácz, R., Bartholy, J. and Bartha, E.B. 2013. Analysis of projected changes in the occurrence of heat waves in Hungary. Advances in Geosciences 35. 115-122.

Rupp, R.F., Vásquez, N.G. and Lamberts, R. 2015. A review of human thermal comfort in the built environment. Energy and Buildings 105. 178-205.

Spagnolo, J. and DE Dear, R. 2003. A field study of thermal comfort in outdoor and semi-outdoor environments in subtropical Sydney Australia. Building and Environment 38. 721-738. 
Tung, C.-H., Chen, C.-P., Tsai, K.-T., Kántor, N., Hwang, R.-L., Matzarakis, A. and Lin, T.-P. 2014. Outdoor thermal comfort characteristics in the hot and humid region from a gender perspective. International Journal of Biometeorology 58. 1927-1939.

UNFPA 2011. The state of world population 2011. Report of the United Nations Population Fund. New York, UNFPA.

UNGER, J. 1996. Heat island intensity with different meteorological conditions in a medium-sized town: Szeged, Hungary. Theoretical and Applied Climatology 54. 147-151.

Unger, J., Lelovics, E. and GÁL, T. 2014. Local Climate Zone mapping using GIS methods in Szeged. Hungarian Geographical Bulletin 63. 29-41.

YAHIA, M.W. and JoHANsson, E. 2013. Evaluating the behaviour of different thermal indices by investigating various outdoor urban environments in the hot dry city of Damascus, Syria. International Journal of Biometeorology 57. 615-630.
YANG, W., Wong, N.H. and Jusuf, S.K. 2013a. Thermal comfort in outdoor urban spaces in Singapore. Building and Environment 5. 426-435.

YANG, W., Wong, N.H. and Zhang, G. 2013b. A comparative analysis of human thermal conditions in outdoor urban spaces in the summer season in Singapore and Changsha, China. International Journal of Biometeorology 57. 895-907.

YIN, J.F., ZHENG, Y.F., Wu, R.J., TAN, J.G., YE, D.X. and WANG, W. 2012. An analysis of influential factors on outdoor thermal comfort in summer. International Journal of Biometeorology 56. 941-948.

Zeng, Y. and Dong, L. 2015. Thermal human biometeorological conditions and subjective thermal sensation in pedestrian streets in Chengdu, China. International Journal of Biometeorology 59. 99-108. 


\title{
Ukraine in Maps
}

\author{
Edited by: Kocsis, K., Rudenko, L. and Schweitzer, F.
}

\author{
Institute of Geography National Academy of Sciences of Ukraine \\ Geographical Research Institute Hungarian Academy of Sciences. \\ Kyiv-Budapest, 2008, 148 p.
}

Since the disintegration of the USSR, the Western world has shown an ever-growing interest in Ukraine, its people and its economy. As the second-largest country in Europe, Ukraine has a strategic geographical position at the crossroads between Europe and Asia. It is a key country for the transit of energy resources from Russia and Central Asia to the European Union, which is one reason why Ukraine has become a priority partner in the neighbourhood policy of the EU. Ukraine has pursued a path towards the democratic consolidation of statehood, which encompasses vigorous economic changes, the development of institutions and integration into European and global political and economic structures. In a complex and controversial world, Ukraine is building collaboration with other countries upon the principles of mutual understanding and trust, and is establishing initiatives aimed at the creation of a system that bestows international security.

This recognition has prompted the Institute of Geography of the National Academy of Sciences of Ukraine (Kyiv) and the Geographical Research Institute of the Hungarian Academy of Sciences (Budapest) to initiate cooperation, and the volume entitled "Ukraine in Maps" is the outcome of their joint effort. The intention of this publication is to make available the results of research conducted by Ukrainian and Hungarian geographers, to the English-speaking

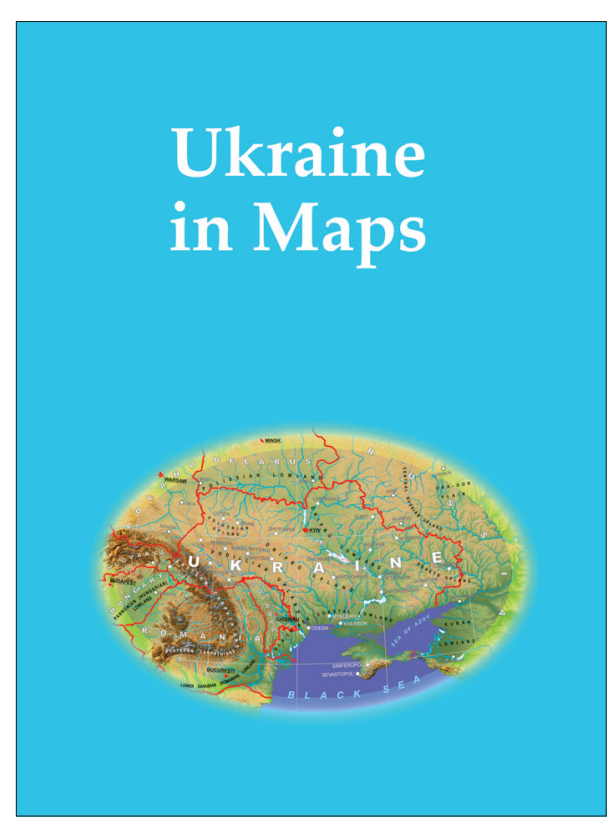
public. This atlas follows in the footsteps of previous publications from the Geographical Research Institute of the Hungarian Academy of Sciences. Similar to the work entitled South Eastern Europe in Maps $(2005,2007)$, it includes 64 maps, dozens of figures and tables accompanied by an explanatory text, written in a popular, scientific manner. The book is an attempt to outline the geographical setting and geopolitical context of Ukraine, as well as its history, natural environment, population, settlements and economy. The authors greatly hope that this joint venture will bring Ukraine closer to the reader and make this neighbouring country to the European Union more familiar, and consequently, more appealing.

Price: EUR 35.00

Order: Geographical Institute RCAES MTA Library

H-1112 Budapest, Budaörsi út 45.

E-mail: magyar.arpad@csfk.mta.hu 